\title{
The impact of cementation on permeability and strength of porous limestone
}

\author{
Patrick Baud*, Institut de Physique du Globe de Strasbourg (UMR 7516 CNRS, Université de Strasbourg/EOST), France
} Teng-fong Wong, Earth System Science Programme, Faculty of Science, The Chinese University of Hong Kong, Hong Kong Ulrike Exner, Department of Geology and Palaeontology, Natural History Museum, Vienna, Austria,

Fanbao Meng, Earth System Science Programme, Faculty of Science, The Chinese University of Hong Kong, Hong Kong

Copyright 2019, SBGf - Sociedade Brasileira de Geofísica

This paper was prepared for presentation during the $16^{\text {th }}$ International Congress of the Brazilian Geophysical Society held in Rio de Janeiro, Brazil, 19-22 August 2019.

Contents of this paper were reviewed by the Technical Committee of the $16^{\text {th }}$ International Congress of the Brazilian Geophysical Society and do not necessarily represent any position of the SBGf, its officers or members. Electronic reproduction or storage of any part of this paper for commercial purposes without the written consent of the Brazilian Geophysical Society is prohibited.

\section{Abstract}

We studied mechanical compaction, strain localization and permeability in Leitha limestone. This carbonate from the area of Vienna (Austria) occurs with a broad range of grain sizes and porosity, due to changes in depositional regime and degree of cementation. Our new mechanical data revealed a simple relation between porosity and mechanical strength. Increasing cementation and decreasing porosity led to a significant increase of the rock strength both in the brittle and ductile regimes. Micromechanical modelling showed that the dominant micromechanisms of inelastic deformation in Leitha limestone are pore-emanated microcracking in the brittle regime, and grain crushing and cataclastic pore collapse in the ductile regime. Microstructural analysis revealed the development of compaction bands in some of the less cemented samples, while more cemented end-members failed by cataclastic flow in the compactant regime. In contrast to mechanical strength, permeability of Leitha limestone was not significantly impacted by increasing cementation and decreasing porosity.

\section{Introduction}

A fundamental understanding of the inelastic behavior of porous rocks and its implication on fluid flow at various scales is needed in order to analyze deformation and failure in many sedimentary successions. In porous carbonates, the phenomenology of brittle failure and inelastic compaction as reported by laboratory studies, is similar to that of sandstone over a wide range of porosities (WONG and BAUD, 2012). Carbonate rocks are widely recognized to have pore geometry that is significantly more complex than other sedimentary rocks (CHOQUETTE and PRAY, 1970). The pore size in a carbonate rock may span over a very broad range, with a distribution that is often bimodal, including a significant subset of microporosity (BAECHLE et al., 2008). Field studies on carbonate formations (see for example TONDI et al., 2006) suggest that various mechanisms such as grain rotation, pore-collapse, grain crushing, crystal plasticity and pressure solution may lead to inelastic compaction and strain localization in carbonates. Additional complexity arises from the fact that these mechanisms are obviously influenced by microstructural parameters, such as the degree of cementation or the spatial distribution of macro- and micropores. Possibly because of such complex situation, significant variability was observed both in the brittle strength (BAUD et al., 2014) and the onset of inelastic compaction of carbonates, even for samples coming from the same sedimentary unit (DAUTRIAT et al., 2011). We investigated systematically the mechanical behavior and permeability variations in a porous carbonate from the Vienna Basin in Austria. Our main objective was to study how cementation influences the micromechanics of failure and permeability in a limestone formation.

\section{Material studied and experimental methods}

For this study, we chose Leitha limestone, a bioclast carbonate of Middle Miocene age from the Vienna Basin in Austria. The limestone consists predominantly of one allochemical component (bioclasts) and interparticular macropores. These pre-existing macropores have been coated with sparite calcite cement. Although there are micropores embedded in some of the bioclasts, they contribute relatively little to the total porosity, which varies significantly $(18-31 \%)$ in the formation, primarily due to variable degree of cementation. Microstructural analysis revealed a small proportion of intragranular microporosity in the highest porosity samples (Figure 1a). This microporosity disappeared with increasing cementation and in the low porosity end members, the pore space was almost exclusively composed of macropores (Figure 1b).

(a)

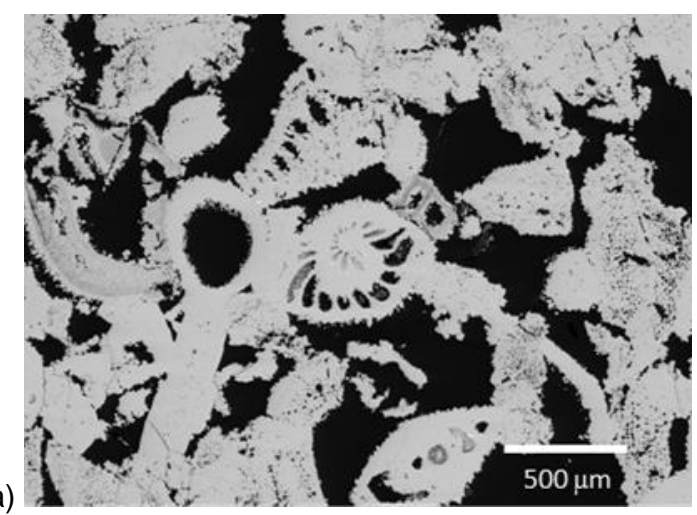


(b)

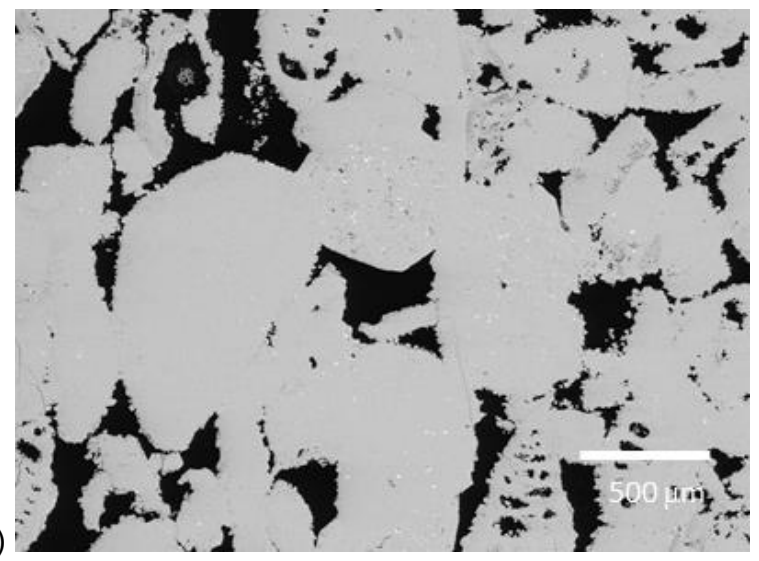

Figure 1 - Backscattered SEM images of undeformed Leitha limestone of (a) $31 \%$ and (b) $21 \%$ initial porosity. No significant microporosity was observed in the sample of $21 \%$ porosity.

Cylindrical samples $(20 \mathrm{~mm}$ in diameter and $40 \mathrm{~mm}$ in length) were cored orthogonal to the sedimentary bedding from several blocks collected in the quarry Hummel St. Margarethen/Burgenland near Vienna (Austria). The samples were dried in vacuo at $40^{\circ} \mathrm{C}$ for a minimum of 48h. Porosity was measured by helium pycnometer. Permeability was measured using gas (Nitrogen) by the steady-state flow technique at a confining pressure of 2 MPa (see FARQUHARSON et al., 2016 for details). The samples were then saturated with deionized water. Conventional triaxial compression experiments were performed at room temperature following the protocol of $B A U D$ et al. (2015). Jacketed samples were deformed in drained conditions (with a pore pressure of $5 \mathrm{MPa}$ ) at a nominal strain rate of $10^{-5} / \mathrm{s}$ and at confining pressures ranging from 5 to $160 \mathrm{MPa}$.

\section{Results}

The difference between the confining pressure and pore pressure will be referred to as the "effective pressure" in the following. Hydrostatic data are presented in Figure 2. The hydrostats could be separated in three successive stages: (1) The first nonlinear part at low effective pressures corresponds to microcrack closure. (2) Then the behavior becomes poroelastic and (3) beyond a critical pressure denoted $P^{\star}$ (WONG et al., 1997), we observed an acceleration of the compaction corresponding to the onset of grain crushing and pore collapse. $P^{\star}$ can be therefore seen as the onset of inelastic compaction. $P^{\star}$ increased quickly and regularly with decreasing porosity, from $28 \mathrm{MPa}$ at $31 \%$ to 125 $\mathrm{MPa}$ at $18 \%$. We noted however that if the compressibility of Leitha limestone decreased significantly when porosity decreased from $31 \%$ to $25 \%$ (from about a factor 3 ), it did not change between $25 \%$ and $21 \%$, yet again decreased between $21 \%$ and $18 \%$. Most of the hydrostatic experiments were stopped when the plastic volumetric reached around $4 \%$.

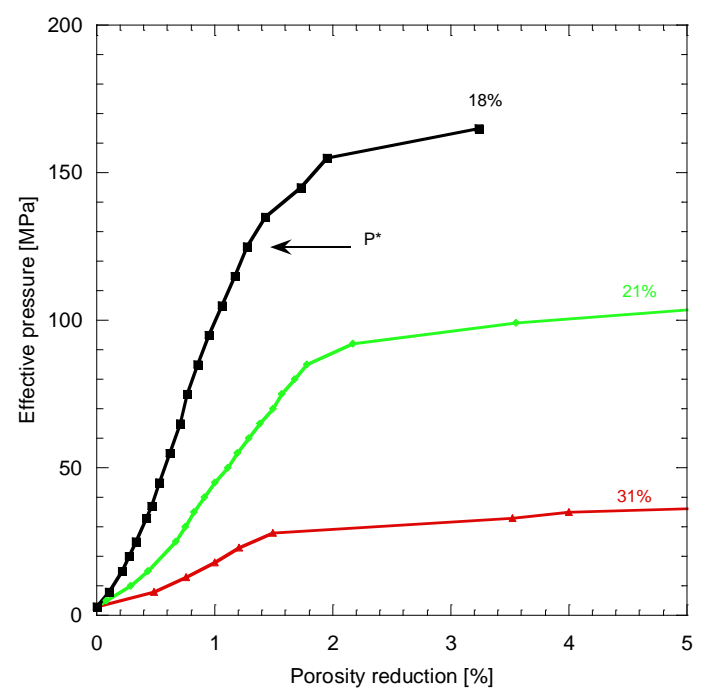

Figure 2 - Effective pressure as a function of porosity reduction in hydrostatic experiments. Arrow indicates the critical pressure $P^{*}$ for the onset of pore collapse. The initial porosity of the samples is indicated next to the curves.

Representative triaxial data for samples of porosities $21 \%$ and $31 \%$ are presented in Figure 3 . Brittle behavior was only observed for the low porosity end-members at effective pressures up to $20 \mathrm{MPa}$. At all tested pressures the curves were punctuated by episodic stress drops, in some cases of high amplitude (up to $5 \mathrm{MPa}$ ). Previous studies showed that this is usually an indicator that some compaction localization occurred in the samples (BAUD et al., 2004; CHEUNG et al., 2012).

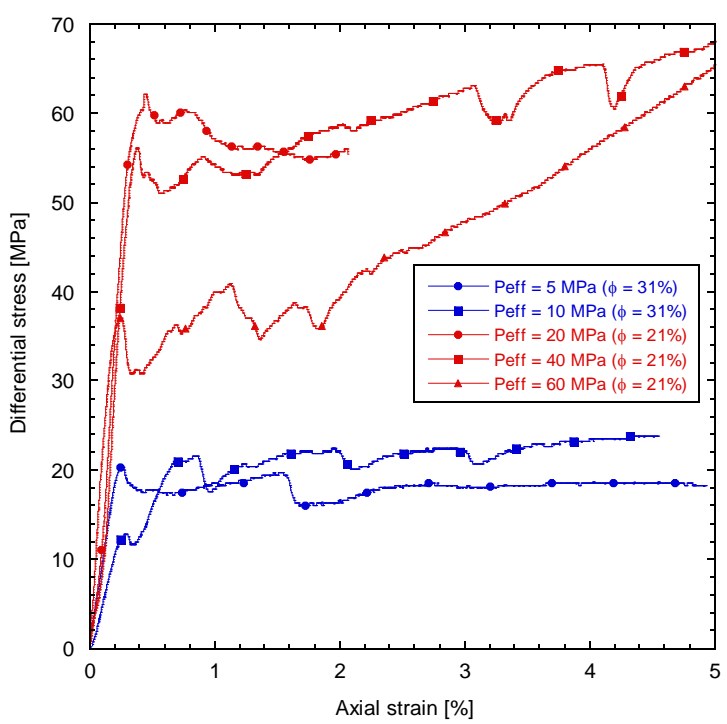

Figure 3 - Selected mechanical data for triaxial compression experiments on Leitha limestone samples of initial porosities $31 \%$ (blue) and $21 \%$ (red). Differential stress is plotted as a function of axial strain. 
Significant strain hardening was only observed in the low porosity end-members when deformed at relatively high effective pressures. All the tested samples experienced shear-enhanced compaction (Figure 4).

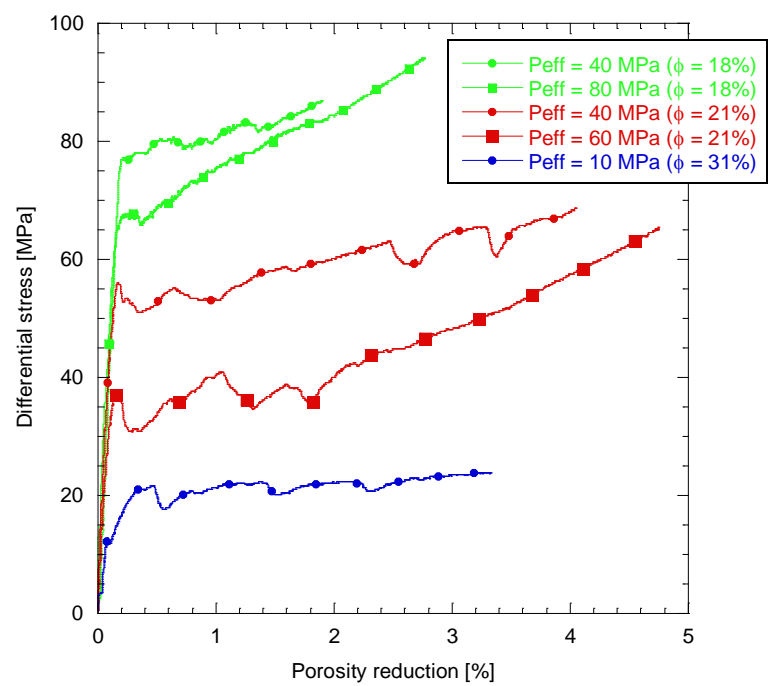

Figure 4 - Selected mechanical data for triaxial compression experiments on Leitha limestone samples of initial porosities 18\% (green), 21\% (red) and 31\% (blue). Differential stress is plotted as a function of porosity reduction.

Our triaxial and hydrostatic data on samples of initial porosity $18 \%, 21 \%$, and $31 \%$ are summarized in Figure 5 where the critical pressures $P^{*}$ and onset of shearenhanced compaction are presented in the stress space. The triaxial datasets map out a single compactant yield envelope as it has been previously shown for other porous carbonates (BAUD et al., 2009; Jl et al., 2015). Our triaxial data confirmed the large increase in strength induced by the cementation of Leitha limestone. We also note that the yield caps are almost linear for the samples of 21 and $31 \%$ initial porosity.

Deformed samples were then saturated with epoxy and polished petrographical thin sections were prepared in the vertical direction on the whole sample length for SEM analysis at the Department of Lithospheric Research, University of Vienna. Failure modes identified by visual inspection and microstructural analysis are shown next to the failure envelopes in Figure 5. Compactive shear bands were observed in samples of 18 and $21 \%$ porosity deformed at low effective pressures. At higher effective pressures, homogeneous cataclastic flow developed in all tested samples with these initial porosities. A somehow different behavior was observed in the high porosity endmembers (31\% initial porosity). Diffuse bands were visible in samples deformed at low effective pressures. Intense grain crushing and pore collapse were evident inside the diffuse bands (Figure 6). A similar failure mode was recently revealed in Saint-Maximin limestone of $37 \%$ porosity by BAUD et al., 2017a) by Acoustic emission monitoring. We inferred a porosity reduction of about $10 \%$ in the compaction bands. This was confirmed by complementary imaging by X-ray Computed microtomography (BAUD et al., 2017b).

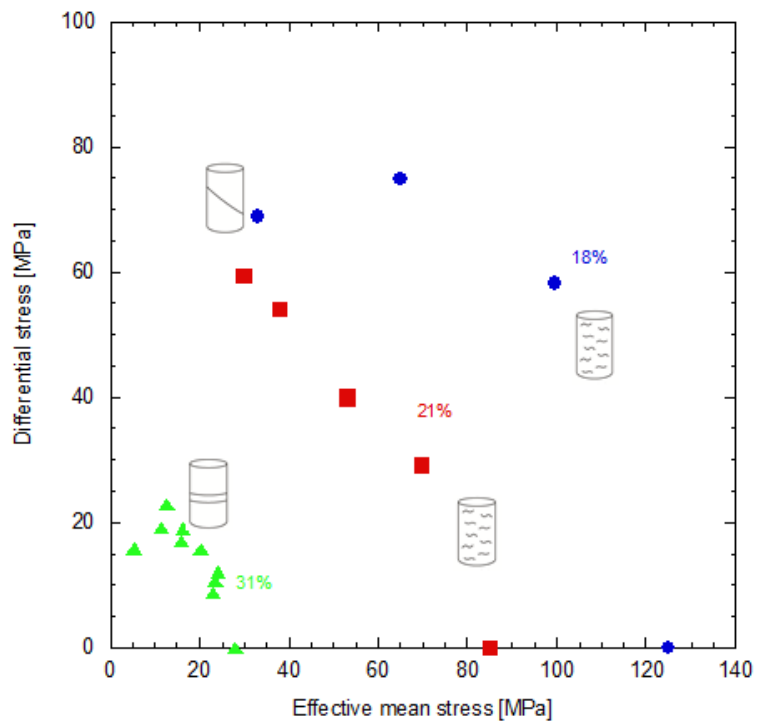

Figure 5 - Compactive yield caps for the onset of shearenhanced compaction in the effective mean stress and differential stress space for Leitha limestone of initial porosity, $18 \%$ (blue circles), $21 \%$ (red squares) and $31 \%$ (green triangles). Cartoons next to the caps give the failure modes based on visual inspection of the samples and microstructural analysis.

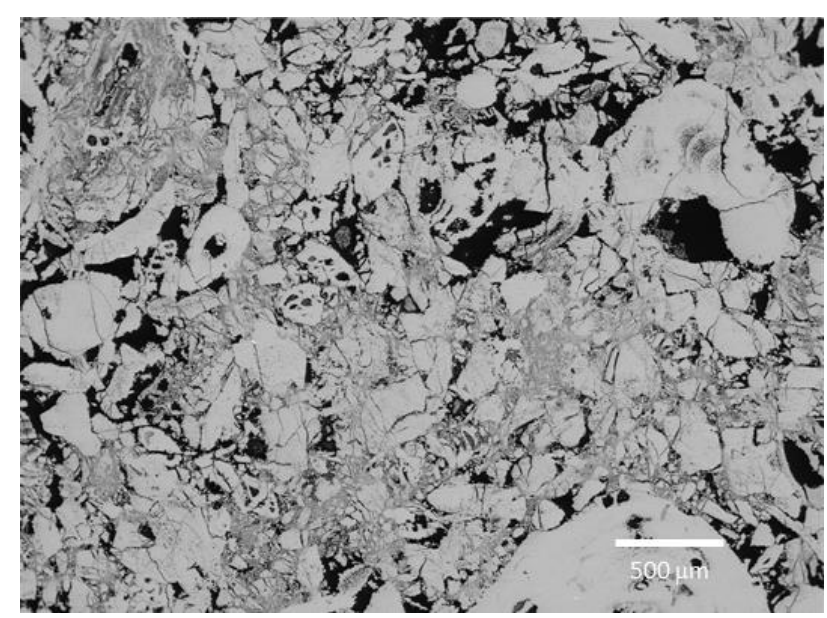

Figure 6 - SEM micrograph showing intense grain crushing and pore collapse in a sample of Leitha limestone of initial porosity $31 \%$, deformed at an effective pressure of $10 \mathrm{MPa}$.

There is an overall trend for permeability of Leitha limestone to increase with increasing porosity (Figure 7). A moderate decrease from 8 to $2 \times 10^{-12} \mathrm{~m}^{2}$ was observed with porosity decreasing from $31 \%$ to $21 \%$, followed by a dramatic decrease by at least one order of magnitude when porosity decreased further to $18 \%$. 


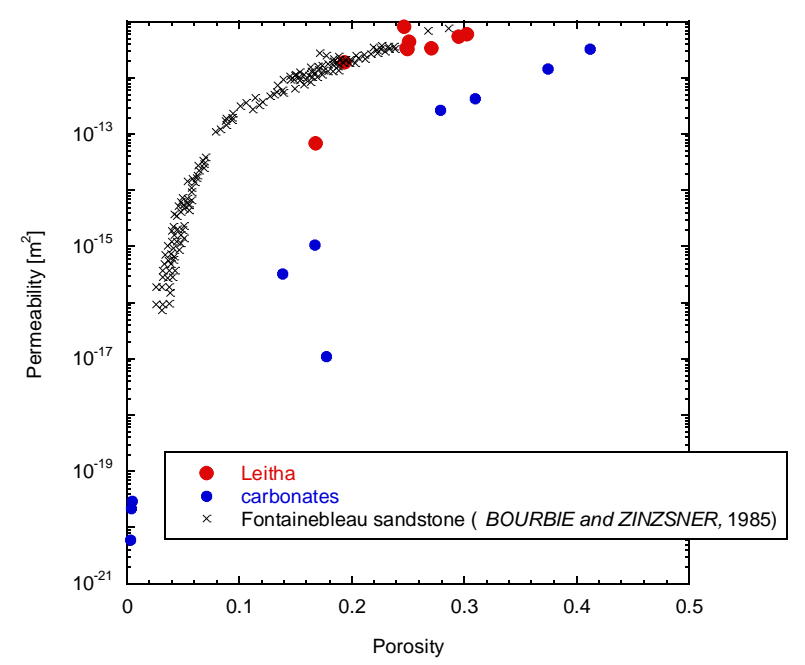

Figure 7 - Permeability as a function of porosity for Leitha limestone (red circles) published data on Fontainebleau sandstone from BOURBIE and ZINZSNER (1993) (black crosses) and a compilation of data on limestone (blue circles) from HEAP et al. (2014), RUSTICHELLI et al. (2015) and Jl et al. (2015).

The permeability of Leitha is about one order above the trend suggested by published data obtained using the same experimental set-up and conditions by HEAP et al. (2014), RUSTICHELLI et al. (2015) and Jl et al. (2015). Our microstructural observations suggested that this is due to large pore sizes in this rock (Figure 1). We applied the equivalent channel model (WALSH and BRACE, 1984) to our permeability data on Leitha. According to this model, on the average the hydraulic radius in Leitha limestone did not undergo much change, even when cementation had reduced the porosity from $31 \%$ to $21 \%$. This would imply that cement in these samples mainly accumulated in the vicinity of grain contacts or nodal pores, without significantly impacting the throats that control transport.

Comparison with data of BOURBIE and ZINZSNER (1985) on Fontainebleau sandstone suggested that if the Leitha limestone had undergone more extensive cementation, then the behavior in this sandstone would provide a proxy for corresponding changes in the permeability.

\section{Conclusions}

In this study, sampling carbonates from the same formation over a large interval of porosity, we showed that it is possible to obtain a clear relation between porosity and mechanical strength both in the brittle and ductile regimes. Larger porosity in Leitha limestone resulted in a spectacular decrease of its strength in both regimes. Simple quadratic relations porosity-strength based on our new data could potentially be used as guidance in field scale problems. The main micromechanism of inelastic compaction in Leitha limestone is grain crushing, in contrast with other limestones with a dual porosity ( $\mathrm{ZHU}$ et al., 2010). Compaction bands were observed in the less cemented samples of Leitha limestone (31\% porosity) but not in more cemented ones. Our data suggest that increasing cementation created a more heterogeneous structure, in which compaction localization could not develop extensively. Based on our microstructural observations, it is possible that subtle changes in cementation could explain why compaction bands were or were not reported in previous field and laboratory studies, sometimes performed on comparable rocks. Future research involving in situ CT imaging will be performed to better understand the nucleation and growth of compaction bands in limestone.

Finally, we found that porosity differences did not have significant influence on the permeability of Leitha limestone, in contrast to mechanical strength. This is essentially due to the existence of a backbone of connected large macropores in all our samples, which also explains the high permeability (in the range of 2-5 Darcy) of Leitha in comparison to other limestones with similar porosities. In fact, the permeability of Leitha is very similar to published data on Fontainebleau sandstone of comparable porosity. An outstanding question for future work would be to which extend mechanical and/or chemical compaction could significantly impact such high permeability.

\section{Acknowledgments}

This study was partially funded by the Hong Kong Research Grants Council GRF14323916, a Direct Grant of the CUHK Faculty of Science, the France-Hong Kong Collaborative Program Procore 30805PM and FCUHK405/16, and by CNRS (PICS 07961).

\section{References}

BAECHLE, G. T., COLPAERT, A., EBERLI, G. P., and WEGER, R. J. Effects of microporosity on sonic velocity in carbonate rocks. The Leading Edge (August), 10121018, 2018.

BAUD, P., KIEIN, E., and WONG, T.-f. Compaction localization in porous sandstones: spatial evolution of damage and acoustic emission activity. Journal Structural of Geology, 26, 603-624, 2004.

BAUD, P., VINCIGUERRA, DAVID, C., CAVALLO, A., WALKER, E., and REUSCHLE, T. Compaction and Failure in High Porosity Carbonates: Mechanical Data and Microstructural Observations. Pure and Applied Geophysics, 166, 869-898, 2009.

BAUD, P., WONG, T.-f., and Zhu, W. Effects of Porosity and Crack Density on Compressive Strength of Rocks, International Journal of Rock Mechanics and Mining Science, 67, 202-211, 2014.

BAUD, P., REUCHLE, T., JI, Y., CHEUNG, C., and WONG, T.-f. Mechanical compaction and strain localization in Bleurswiller sandstone. Journal of Geophysical Research Solid Earth, 120, doi:10.1002/2015JB012192, 2015. 
BAUD, P., SCHUBNEL, A., HEAP, M. J., and ROLLAND, A. Inelastic compaction in high porosity limestone monitored using acoustic emissions. Journal of Geophysical Research Solid Earth, 122(12), 9989-10008, 2017a.

BAUD, P., EXNER, U., LOMMATSCH, M., REUSCHLE, T., and WONG, T.-f. Mechanical behavior, failure modes and transport properties in a porous limestone. Journal of Geophysical Research Solid Earth, 122(9), 7363-7387, 2017b.

BOURBIE, T., and ZINZSNER, B. Hydraulic and acoustic properties as a function of porosity in Fontainebleau sandstone, Journal of Geophysical Research, 90, 11524$11532,1985$.

CHEUNG, C., BAUD, P., and WONG, T.-F. 2012. Effect of grain size distribution on the development of compaction localization in porous sandstone. Geophysical Research Letters, 39, L21302.

CHOQUETTE, P. W., and PRAY, L. C. Geologic nomenclature and classification of porosity in sedimentary carbonates. AAPG Bulletin, 54, 207-250, 1970.

DAUTRIAT, J., GLAND, N., DIMANOV, J., and RAPHANEL, J. Hydromechanical behavior of heterogeneous carbonate rock under proportional triaxial loading. Journal of Geophysical Research Solid Earth, 116, 2011.

FARQUHARSON, J. I., HEAP, M. J., LAVALLEE, Y., VARLEY, N. R., and BAUD, P. Evidence for permeability heterogeneity in volcanic conduits. Journal of Volcanology and Geothermal Research, 323, 163-185, 2016.

HEAP, M. J., BAUD, P., REUSCHLE, T., and MEREDITH, P. G. Stylolites in limestones: barriers to flow? Geology, 42, 51-54, 2014.

JI, Y., HALL, S., BAUD, P., and WONG, T.-F. Characterization of pore structure and strain localization in Majella limestone by X-ray computed tomography and digital image correlation. Geophysical Journal International, 200, 701-719, 2015.

RUSTICHELLI, A., TONDI, E., KORNEVA, I., BAUD, P., VINCIGUERRA, S., AGOSTA, F., REUSCHLE, T., and JANISECK, J. M. Bedding parallel stylolites in shallowwater limestone successions of the Apulian Carbonate Platform (central-southern Italy), Italian Journal of Geosciences, 134 (3), 513-534, 2015.

TONDI, E., ANTONELLINI, M.A., AYDIN, A., MARCHEGIANI, L., and CELLO, G. The role of deformation bands, stylolites and sheared stylolites in fault development in carbonate grainstones of Majella Mountain, Italy. Journal of Structural Geology, 28, 376391, 2006.

WALSH, J. B., and BRACE, W. F. The effect of pressure on porosity and the transport properties of rock. Journal of Geophysical Research Solid Earth, 89(B11), 9425-9431, 1984.

WONG, T.-F., DAVID, C., and ZHU, W. The transition from brittle faulting to cataclastic flow in porous sandstone: Mechanical deformation. Journal Geophysical Research, 102, 3009-3025, 1997.

WONG, T.-F., and BAUD, P. The brittle-ductile transition in porous rock: A review. Journal of Structural Geology, 44, 25-53, 2012.

ZHU, W., BAUD, P., and WONG, T.-F. Micromechanics of cataclastic pore collapse in limestone. Journal of Geophysical Research Solid Earth. 115 (B04405), 2010. 